\title{
Pressões em silo armazenador de produtos pulverulentos alimentícios a partir da norma Eurocode 1
}

\author{
Pressures in silo storer of food powders from Eurocode 1 standard \\ Presiones en el almacener de silos de alimentos en polvo del Eurocódigo 1
}

Recebido: 20/09/2021 | Revisado: 27/09/2021 | Aceito: 28/09/2021 | Publicado: 29/09/2021

\author{
Diego José Araújo Bandeira \\ ORCID: https://orcid.org/0000-0002-6245-9875 \\ Universidade Federal de Campina Grande, Brasil \\ E-mail: diegoimperium8@gmail.com \\ Ariadne Soares Meira \\ ORCID: https://orcid.org/0000-0001-8740-9009 \\ Universidade Federal de Campina Grande, Brasil \\ E-mail: ariadnesm_eng @hotmail.com \\ Patrício Gomes Leite \\ ORCID: https://orcid.org/0000-0001-5500-7865 \\ Universidade Federal do Maranhão, Brasil \\ E-mail: pgomesleite@gmail.com \\ Marcia Janiele Nunes da Cunha Lima \\ ORCID: https://orcid.org/0000-0003-3697-8724 \\ Universidade Federal de Campina Grande, Brasi \\ E-mail: marciacunhalima87@hotmail.com \\ Antônio Nunes de Oliveira \\ ORCID: https://orcid.org/0000-0001-5697-8110 \\ Instituto Federal do Ceará, Brasil \\ E-mail: nunes.vieira@ifce.edu.br \\ Rodolfo Ramos Castelo Branco \\ ORCID: https://orcid.org/0000-0002-9034-7985 \\ Universidade Federal de Campina Grande, Brasil \\ E-mail: castelobrancorodolfo@gmail.com \\ Keviane Pereira Aragão \\ ORCID: https://orcid.org/0000-0002-2237-130X \\ Universidade Federal de Campina Grande, Brasil \\ E-mail: kevianearagao@gmail.com \\ Anúbes Pereira de Castro \\ ORCID: https://orcid.org/0000-0002-3795-5666 \\ Universidade Federal de Campina Grande, Brasil \\ E-mail: anubescastro@gmail.com
}

\begin{abstract}
Resumo
Embora, estudos estejam sendo realizados, a determinação da magnitude e distribuição das pressões durante a descarga ainda apresenta dificuldades consideráveis, uma vez que se trata de um fenômeno complexo em que as pressões dependem, entre outras coisas e da maneira como o material armazenado flui. Sendo assim, o presente trabalho emprega as equações apresentadas na norma BS EN 1991/4 (2006) para determinar a assíntota representativa da distribuição das pressões ao longo do corpo do silo que apresenta 8 metros de altura e 2 metros de diâmetro efetivo possível de armazenar 4 produtos alimentícios pulverulentos, e. Silo este, confeccionado com chapas de aço liso, munido de tremonha concêntrica com inclinação de $60^{\circ} \mathrm{com}$ a horizontal. As propriedades de fluxo foram determinadas utilizando o Jenike Shear Cell. Obteve-se resultado semelhante das pressões entre os produtos amido de milho e a fécula de batata por apresentarem similaridade na granulometria. Os produtos em estudo são coesivos e não apresentam fluxo fácil, porém, em nenhum dos casos as pressões de atrito ao longo da parede se distinguiram entre o carregamento e o descarregamento.
\end{abstract}

Palavras-chave: Curva de pressão; Carregamento; Descarregamento.

\begin{abstract}
Although, studies are being carried out, the determination of the magnitude and distribution of pressure during unloading still presents considerable difficulties, because it is a complex phenomenon in which the pressures depend, among other things and the way the stored material flows. So, the present work using four food products in powder form, and employs the equations given in the standard BS EN 1991/4 (2006) to determine the Asymptote distribution representative of pressures along the body of the silo which features 8 meters high and 2 meters in diameter. This silo,
\end{abstract}


made with smooth steel plates with concentric hopper with inclination of $60^{\circ}$ with the horizontal. The flow properties were determined using the Jenike Shear Cell. A similar result was obtained from the pressures between the products cornstarch and potato starch by similarity in particle size. The products under review are cohesive and present no easy flow, however, in none of the cases the pressures of friction along the wall have distinguished themselves between charge and discharge.

Keywords: Pressure curve; Charge; Discharge.

\section{Resumen}

Aunque, se están realizando estudios, la determinación de la magnitud y distribución de las presiones durante la descarga todavía presenta dificultades considerables, ya que es un fenómeno complejo en el que dependen las presiones, entre otras cosas y la forma en que fluye el material almacenado. Así, el presente trabajo emplea las ecuaciones presentadas en bs EN 1991/4 (2006) para determinar el asisto representativo de la distribución de presiones a lo largo del cuerpo del silo que tiene 8 metros de altura y 2 metros de diámetro efectivo posible para almacenar 4 productos alimenticios en polvo, e. Este silo, hecho con placas planas de acero, equipado con tremonha concéntrica con inclinación de $60^{\circ}$ con horizontal. Las propiedades de flujo se determinaron utilizando Jenike Shear Cell. Se obtuvo un resultado similar de las presiones entre el almidón de maíz y la fécula de patata porque presentaban similitud en la granulometría. Los productos en estudio son cohesivos y no presentan un flujo fácil, sin embargo, en ninguno de los casos las presiones de fricción a lo largo de la pared se distinguieron entre carga y descarga.

Palabras clave: Curva de presión; Carga; Descarga.

\section{Introdução}

O Brasil possui uma limitada capacidade de armazenamento, que não acompanha a produção agrícola do país, o que proporciona perdas econômicas para os produtores e, desta forma, a construção de silos verticais surge como uma alternativa para solução deste problema (Bandeira et al.,2020).

Os silos verticais representam uma saída para os problemas de armazenamento e são amplamente utilizados em muitas indústrias, tais como mineração, metalurgia, e indústrias de alimentos (Liu et al.,2014). Os projetos de silos para armazenamento de produtos agrícolas segundo Carríon (2015) e Dornelas et al (2021) dependem diretamente do cálculo das propriedades físicas e de fluxo desses produtos, a das pressões que estes produtos exercem sobre as paredes e estrutura do silo, visando o seu dimensionamento de maneira segura e econômica.

Assim, para a laboração de um projeto de silo a Eurocode 1 (2006), norma europeia para cálculo de pressões em silos, recomenda alguns parâmetros e características para silos e equações empíricas para a distribuição das pressões ao longo do silo, partindo de propriedades experimentais de fluxo tais como ângulo de atrito interno e peso específico do produto.

As pressões que envolvem o projeto de um silo armazenador são o ponto que ainda apresenta fragilidades para que se tenha total conhecimento, pois tendo em vista o processo de descarga do silo Ding (2014) enfatiza que a maioria das normas define a pressão de descarregamento do silo usando simplesmente um multiplicador conhecido como fator de sobrepressão, aplicado à pressão de carregamento.

Segundo Madrona (2009); Lopes Neto, Meira e Nascimento (2017) e Meira et al. (2020), um dos principais entraves para a determinação das pressões de carregamento e descarregamento de um silo armazenador é a atuação do produto armazenado sobre as paredes do silo, que é individualizada e específica para cada tipo de produto.

Um dos problemas mais significativos em projeto de silos é a exata predição da distribuição de cargas no corpo do silo, com especial atenção para as pressões exercidas nas paredes em virtude do empuxo do produto armazenado (Bandeira et al.,2021).

As pressões nas paredes do silo durante o carregamento e o armazenamento podem ser bem representadas por equações de pressão idealizadas por Janssen (1895), no entanto, segundo Yin (2015), não há consenso quanto à pressão no descarregamento devido ao tempo e as variações espaciais.

De acordo com estudos Ding (2014) e Fank et al. (2018), as pressões que ocorrem durante a descarga não são 
perfeitamente entendidas, levando-se em conta que a pressão no início da descarga é muito próxima da pressão no final da descarga. Também pode ser notada uma discrepância existente entre a pressão calculada e a medida experimentalmente na extremidade superior da tremonha.

Fank (2015) destaca a distribuição de tensões em um ponto na massa do produto armazenado constatado ainda que embora a distribuição interna seja praticamente uniforme, assim como o carregamento, a distribuição das pressões nas colunas de sustentação é desuniforme quando ocorrendo o fluxo.

Sendo assim, este trabalho tem por objetivo empregar as equações apresentadas na norma BS EN 1991/4 (2006) para determinar a assíntota representativa da distribuição das pressões ao longo do corpo do silo armazenador para o carregamento e descarregamento de produtos pulverulentos alimentícios.

\section{Metodologia}

Os ensaios de cisalhamento assim como a determinação empírica das pressões ao longo do corpo do silo, foram realizados no Laboratório de Construções Rurais e Ambiência (LaCRA) do Departamento de Engenharia Agrícola da Universidade Federal de Campina Grande (UFCG), Campus de Campina Grande - PB, Brasil.

Foram utilizados nessa pesquisa dois amidos (amido de milho e de arroz), e duas féculas (fécula de batata e de mandioca), adquiridos no comercio local, denominados neste trabalho como AA (amido de arroz), AM (amido de milho), FB (fécula de batata) e FM (fécula de mandioca), os quais apresentam granulometrias similares, sendo classificados como pulverulentos coesivos, com teor de umidade entre 9,8 e $17,5 \%$.

O silo a ser projetado apresenta 2,50 metros de altura corpo do silo e 0,64 metros de diâmetro efetivo, evidenciando uma relação H/D de 4, sendo considerado um silo esbelto segundo a classificação na norma Eurocode1 (2006). Este silo é confeccionado com chapas de aço liso com $1 \mathrm{~mm}$ de espessura, munido de tremonha concêntrica com inclinação de $60^{\circ} \mathrm{com}$ a horizontal também confeccionada em aço liso em mesma espessura do corpo do silo.

Os ensaios de cisalhamento foram realizados em triplicata no aparelho de cisalhamento transversal TSG 70-140 que utiliza a célula de Jenike. O segmento de parede utilizado para a determinação do ângulo de atrito do produto com a parede foi confeccionado como o mesmo material da parede do silo, aço liso.

Para a determinação das assíntotas de pressão dos quatro produtos pulverulentos estudados, utilizou-se a norma estrangeira BS EN 1991/4 (1996) que apresenta equações para tais fins.

As equações seguintes (1-6) foram utilizadas para a determinação das pressões no carregamento dos produtos armazenados.

$$
\begin{aligned}
P h c & =P h o Y j \\
P w c & =\mu P h o Y j \\
P v c & =\frac{P h o}{K} Y j \\
P h o & =\gamma K Z o
\end{aligned}
$$

Onde:

$$
Z o=\frac{1}{K \mu} \frac{A}{U}
$$




$$
Y j=1-e^{\frac{-Z}{Z_{0}}}
$$

Para a determinação das pressões no descarregamento foram utilizadas as seguintes equações:

$$
\begin{aligned}
& P h d=C h P h c \\
& P w d=C w P w c
\end{aligned}
$$

Para silos de paredes finas com uma relação Dc/t >200 e classificados segundo a norma Eurocode 1 como de classes 2 e/ou 3 tem-se os coeficientes de sobrepressão impostos numericamente sobre os valores de:

$$
\begin{aligned}
& C h=1,15 \\
& C w=1,10
\end{aligned}
$$

Com Dc sendo o diâmetro interno ao silo e t a espessura da chapa que compõe a parede do silo.

\section{Resultados e Discussão}

Para a determinação das pressões, a norma BS EN 1991/4 (1996) utiliza informações das propriedades de fluxo dos produtos a serem armazenados demonstrados na Tabela 1.

Tabela1. Propriedades de fluxo dos produtos analisados.

\begin{tabular}{ccccc}
\hline & Ângulo de Atrito interno $\left(\phi_{\mathrm{i}}\right)$ & Efetivo ângulo de atrito $(\delta)$ & $\begin{array}{c}\text { Peso específico consolidado } \\
(\gamma)\end{array}$ & $\begin{array}{c}\text { Coeficiente } \\
\text { de Atrito } \\
(\mu)\end{array}$ \\
\hline AA & 28 & 35 & 8600 & 0,236 \\
AM & 31 & 32 & 6570 & 0,264 \\
FB & 26 & 28 & 8780 & 0,316 \\
FM & 30 & 32 & 6780 & 0,288 \\
\hline
\end{tabular}

Fonte: Autores.

Com relação às propriedades de fluxo, o peso especifico consolidado foi numericamente semelhante para o amido de arroz e a fécula de batata, assim como o amido de milho e a fécula de mandioca. Tais valores foram encontrados por Nascimento e Bandeira (2017) para a ração de suíno em fase de terminação, quando embora sejam produtos distintos, foram classificados como pulverulentos.

Rodrigues et al. (2018) realizando simulações de carregamento e descarregamento em silo vertical, encontram valores de propriedades de fluxo semelhantes a d presente trabalho para o amido de milho.

A partir dos dados obtidos foram geradas representações das assíntotas de pressão horizontal dos produtos com a parede no carregamento e descarregamento (Figura 1), assim como as assíntotas das pressões de atrito com a parede no carregamento e descarregamento (Figura 2), do amido de arroz, amido de milho, fécula de batata e fécula de mandioca. 
Figura 1. Pressões horizontais de carregamento (A) e descarregamento (B) do Amido de Arroz, Amido de Milho, Fécula de Batata e Fécula de Mandioca.
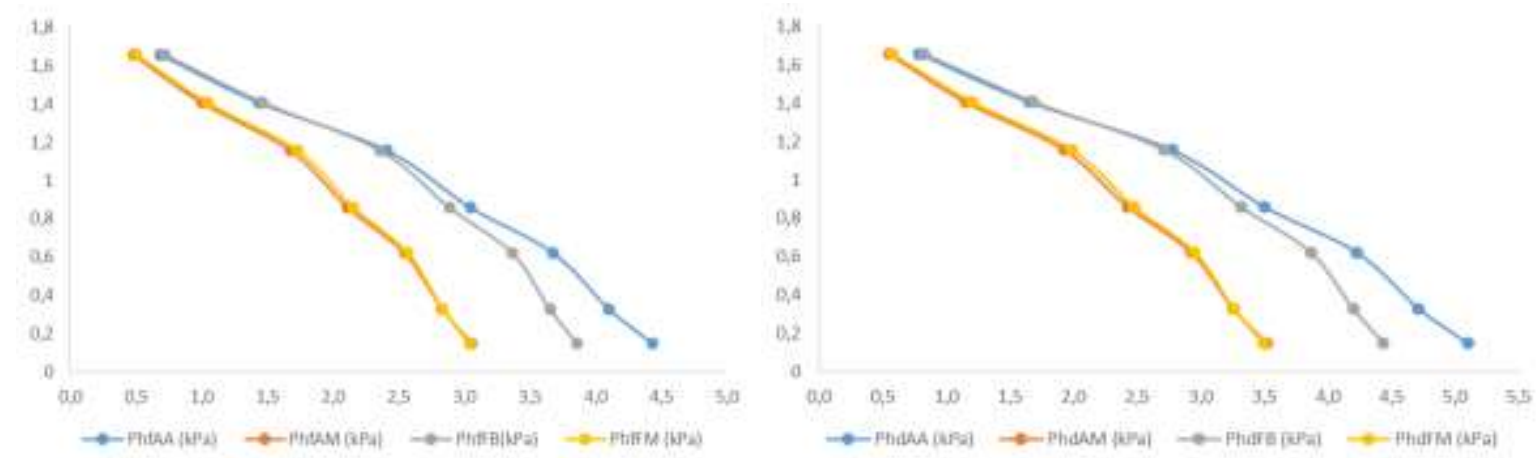

Fonte: Autores.

Figura 2. Pressões de atrito de carregamento (A) e descarregamento (B) do Amido de Arroz, Amido de Milho, Fécula de Batata e Fécula de Mandioca.
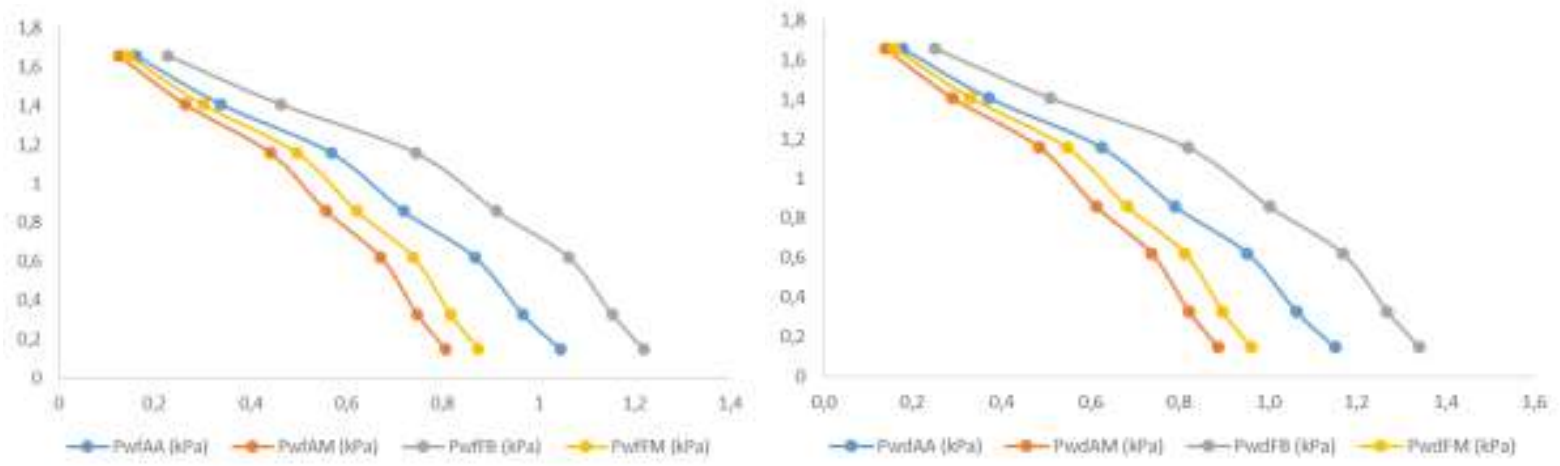

Fonte: Autores.

$\mathrm{O}$ amido de milho e a fécula de mandioca apresentaram similaridade nas pressões tanto no carregamento quanto no descarregamento. Este feito pode ser confirmado pelo fato de ambos os produtos apresentarem granulometria parecida, assim como estarem com mesmo teor de umidade.

Como sugerido pela norma internacional BS EN 1991/4 (2006), as pressões horizontais de descarregamento em todos os produtos foram superiores as pressões horizontais no carregamento haja visto serem multiplicadas por um coeficiente de sobrepressão estipulado pela norma.

Para os quatro produtos em estudo, a pressão horizontal no carregamento é $13, \%$ inferior a pressão horizontal de descarregamento. Assim como a pressão de atrito na parede do silo é 9,5\% inferior no carregamento quando comparado com o descarregamento.

A pressão vertical para o amido de milho e para a fécula de mandioca apresentam valores $25 \%$ abaixo da pressão vertical do amido de arroz e da fécula de batata. A similaridade pode ser expressa pelo fato do amido de milho e da fécula de mandioca apresentarem propriedades fisicas mais aproximadas entre si, assim como o amido de arros e a fécula de batata.

Melo et al. (2018) encontram, para ração suina em fase de terinação, valores de pressão de atrito com diferença de $8 \%$ entre os valores encontrados durante o carregamento e descarregamento, porém, dentro do normatizado pela BS EN 1991/4 (2006). 
Esta variação entre as pressões horizontais é sustentada pela Teoria de Gaylord e Gaylord (1984), a qual afirma que no armazenamento em silo, a pressão vertical tende a ser a maior pressão no estado do carregamento e no descarregamento, com o produto em movimento, a pressão vertical tende a ser a menor pressão.

Dados obtidos á partir de experimentos com açúcar, produto classificado como pulverulento, Meira et al. (2019) encontram valores de pressões durante o descarregamento com assíntotas tendendo a estabilidade próximo ao orifício de descarga. Tal afirmativa também pode ser observada no presente trabalho com os amidos e as féculas.

A norma Eurocode 1 (2006) estabelece para produtos farináceos, um coeficiente de atrito do produto com a parede de aproximadamente 0,24 no limite inferior. No presente trabalho, foi encontrado um valor experimental do coeficiente de atrito do produto com a parede em aço liso, de aproximadamente 0,264 , sendo pouco mais de $10 \%$ superior ao valor normatizado.

\section{Conclusão}

Sabendo-se que a utilização do coeficiente de sobrepressão nas pressões ocorridas no descarregamento dos produtos pulverulentos armazenados, e que, a norma Eurocode 1 preconiza algumas propriedades físicas e de fluxo especificas de cada produto, verificou-se experimentalmente que as variáveis são sutilmente superiores aos valores normatizados, evidenciando assim a individualização das propriedades e a ação das pressões para cada produto pulverulento a ser armazenado.

Sugerimos que as pressões exercidas pelo produto sobre o silo armazenador, sejam analisadas em diferentes percentuais de umidade.

\section{Referências}

BS EN 1991:4. (2006). Eurocode 1. Actions on structures. Silos and tanks, p.112.

Bandeira, D. J. A., Nascimento, J. J. da S., \& Nascimento, J. W. B. do. (2020). Flow analysis of poultry feed in slender vertical silos with inverted cone insert. Research, Society and Development, 9(11), e63091110369. https://doi.org/10.33448/rsd-v9i11.10369

Bandeira, D. J. A., Lima, M. J. N. da C., Oliveira, A. N. de., Branco, R. R. C., Nascimento, K. L. do., Costa, R. F., \& Nascimento, J. J. da S. (2021). Physical and flow properties of common bean cultivars for the design of vertical silos. Research, Society and Development, 10(12), e208101220347. https://doi.org/10.33448/rsd-v10i12.20347

Carrión, A. A. (2015). Grandes silos de almacenamiento de clínker: análisis y priorización. Tese de doutorado. Universitat Politècnica de València. Valencia, 732p.

CONAB - Companhia Nacional de Abastecimento, 2016.

Ding, S., Ji,Y., Senbin, Y., Rotter, J. M., \& Li, Q. (2014). Measurements of pressure and frictional tractions along walls of a large-scale conical shallow hopper and comparison with Eurocode1991-4:2006. Thin-Walled Structures, p. 231-238.

Dornelas, K. C., Silva, V. R., Pessoa, Y. C. C., \& Nascimento, J. W. B. (2021). Propriedades físicas e de fluxo de produtos granulares para projeto de silo. Research, Society and Development, v. 10, n.10, e234101018754.

Fank, M. Z., Christ, M. Z., D., Cardoso, D. L., Willrich, F. L., \& Lorenzi, V. (2015). Coeficiente de transferência de carga nas fundações de silos verticais cilíndricos, Revista Brasileira de Engenharia Agrícola e Ambiental, p. 887-891.

Fank, M. Z., Nascimento, J. W. B., Cardoso, D. L., Meira, A. S., \& Willrich, F. L. (2018). Vertical pressures and compressive friction force in a large silo. Scientific Paper, Agricultural Building and Environment $\bullet$ Eng. agríc. (Online) 38 (4).

Gaylord, E. H., \& Gaylord, C. N. (1895). Design of steel bins for storage of bulk solids. New Jersey: Prentice-Hall, 359p.

Janssen, J. (1895) - Verssuche uber Getreidedruck in Silozellen. Z. Ver. Dtsch. Ing. 1045-1049.

Jenike, A. W. (1964). Storage and flow of silos. Bulletin 123. Salt Lake City: university of utah, 89.

Lopes Neto, J. P., Meira, A. S., \& Nascimento, J. W. B. (2017). Flow properties and pattern flow prediction of food industrial powders. Scientific Paper, Agricultural Building and Environment. Eng. agríc. 37 (04).

Liu, S. D., Zhou, Z. Y., Zou, R. P., Yu, D., \& Pinson, A. B. (2014). Flow characteristics and discharge rate of ellipsoidal particles in a flat bottom hopper. Powder technology, 253, 70-79.

Madrona, F. S., \& Calil Junior, C. (2009). Análise das pressões em silos esbeltos com descarga excêntrica. Cadernos de Engenharia de Estruturas, 37-56. 
Research, Society and Development, v. 10, n. 12, e532101220806, 2021 (CC BY 4.0) | ISSN 2525-3409 | DOI: http://dx.doi.org/10.33448/rsd-v10i12.20806

Meira, A. S., Mota, E. L., Bandeira, D. J. A., Silva, V. R., \& Silva, L. A. (2019). Propriedades de fluxo e pressões para projeto de silo vertical armazenador de açúcares. Revista Engenharia na Agricultura. 27(2), 104-110.

Meira, A. S., Nascimento, J. W. B., Silva, V. R., Nascimento, R. T., \& Soares, H. R. (2020). Análise comparativa de pressões horizontais durante o carregamento em silos verticais metálicos. Pesquisa e Ensino em Ciências Exatas e da Natureza, 4:e1539.

Melo, D. F., Vasconcelos, L. D. S., Meira, A. S., Marques, J. I., \& Leite, P. G. (2018). Pressões e fluxo de ração para suínos em fase de terminação armazenada em silos verticais metálicos. Contecc.

Nascimento, J. W. B., \& Bandeira, D. J. A. (2017). Descarga em silos verticais sem obstrução do fluxo com uso de inserts. Contecc.

Nascimento, F. C, \& Calil Junior, C. (2008). A relação entre as pressões horizontais e verticais em silos elevados: o parâmetro k. Cadernos de Engenharia de Estruturas, 17-37.

Rodrigues, H. C. S., Silva, V. R., Nascimento, R. T., Meira, A. S., \& Nascimento, J. W. B. (2019). Análise de tensões verticais nos produtos armazenados em silos pelo método de elementos finitos. Contecc.

Yin, Wang, Lu, Yong, \& Ooi Jin Y. (2015). A numerical study of wall pressure and granular flow in a flat-bottomed silo. Powder Technology, 43-54. 